\title{
Common Variable Immune Deficiency (CVID) and Gastrointestinal Infections: A Review
}

\author{
Shobha Sehgal, Biman Saikia \\ Department of Immunopathology, \\ Postgraduate Institute of Medical Education and Research, Chandigarh, India
}

Common variable immune deficiency (CVID) is thought to be the second most common immune deficiency disease (PID) next to selective IgA deficiency, accounting for $80 \%$ of cases of PID. The major components of the disorder are immune defects with onset after 24 months of age and presentation usually in young adulthood. ${ }^{1}$ The diagnosis, however, may often be delayed till late adulthood in $80 \%$ of the cases. In the DEF1 French National Study Group the median age of initial symptoms was 18 years. ${ }^{2}$ The prevalence rate is estimated to be 1 in 50,000. ${ }^{3}$ In India there are no large scale studies apart from stray case reports regarding the incidence/ prevalence of CVID suggesting that the diagnosis is being overlooked by the clinicians and diagnosticians. A high degree of suspicion and awareness on the part of the clinician can thus facilitate the diagnosis at an early stage and institution of appropriate timely therapy. Going by the Western statistics, it is envisaged that there would be at least one million cases suffering from various primary immune deficiency syndromes: undiagnosed and untreated, and CVID accounting for an estimated $80 \%$ of these cases, would form a significant disease burden for the country.

\section{Clinical manifestations}

The term "common variable immunodeficiency" is used to designate a group of as yet undifferentiated syndromes characterized by defective antibody formation. The diagnosis however requires exclusion of much more prevalent and common causes of antibody deficiency encountered in day to day clinical practice.

Exclusion criteria: Absence of other antibody deficiency states including X-linked agammaglobulinemia, hyper-IgM

\section{Corresponding Author :}

Dr Shobha Sehgal

Department of Immunopathology,

Postgraduate Institute of Medical Education and

Research, Chandigarh, India

E-mail: shobhasehgal@yahoo.com syndrome, selective IgG subclass deficiency, and Ig heavy chain gene deletions and positive test for anti-HIV antibodies.

\section{Inclusion criteria: ${ }^{4}$}

1. An increased susceptibility to bacterial or fungal infections of the gastrointestinal tracts and the respiratory tract.

2. Associated with low serum-immunoglobulin concentrations below 2 standard deviation of the normal for IgG and one more immunoglobulin isotype.

3. Defective specific-antibody production in response to pneumococcal vaccine or bacteriophage $\mathrm{X}-174$.

Most CVID cases are sporadic while $20 \%$ to $25 \%$ of cases are familial. ${ }^{5}$ The patients are predisposed to recurrent gastrointestinal, ${ }^{6-8}$ pulmonary ${ }^{2}$ and skin infections. Some patients may develop autoimmune diseases, ${ }^{9-11}$ lymphomas, cancers and, ${ }^{12}$ growth hormone deficiency ${ }^{13}$. Approximately $10 \%$ of the patients have coexisting thymoma, an entity known as Good's syndrome. ${ }^{14}$ Although CVID results from a dysfunctional B-cell differentiation, associated T-cell dysregulation may also be seen.

Besides low serum immunoglobulin IgG $(<100 \mathrm{mg})$, a functional defect in $\mathrm{IgG}$ response to immunization by pneumovax and bacteriophage X174 is generally observed along with reduced serum concentration of other immunoglobulins. The patient also fails to mount an adequate response to diphtheria, tetanus, and pneumococcal antigens. Thus these patients repeatedly suffer from infections and have to be given adequate antimicrobial prophylaxis, otherwise they develop bronchiectasis and other infection related complications.

\section{Types of CVID}

There are six types of CVID recognized so far, based on the type of mutation associated:

CVID 1 caused by homozygous mutation in the ICOS 
gene on chromosome $2 \mathrm{q} 33^{15}$

CVID 2 caused by mutation in the TACI gene (TNFRSF13B $)^{16}$

CVID 3 caused by mutation in the CD19 gene ${ }^{17}$

CVID 4 caused by mutation in the BAFFR gene $(\text { TNFRSF13C) })^{18}$

CVID 5 caused by mutation in the CD20 gene ${ }^{19}$

CVID 6 caused by mutation in the CD 81 gene $^{20}$

A large majority of the CVIDs patients, however, remain unclassifiable and the genetic basis undefined.

\section{Spectrum of illness in CVID}

In addition to chronic or recurrent sino-pulmonary infections, many patients develop gastrointestinal manifestations that can be disabling or fatal. ${ }^{21}$ Patients may complain of bloating, pain, nausea, vomiting, diarrhea, weight loss and fatigue. Mouth ulcers with Candida species are generally due to long term use of antibiotics. Approximately 50\% have achlorhydria due to atrophic gastritis and a pernicious anemia like syndrome with increased susceptibility for gastric cancer. ${ }^{12,22}$ The risk for gastric cancer among these patients has been linked to Helicobacter pylori (H.pylori) infection, impaired gastrin secretion and increased rate of mutations in the p53 tumor suppressor gene. Impairment of gastrin secretion is unique to CVID and is not seen in other patients with hypogammaglobulinemia. ${ }^{23,24}$

Esophagus and stomach: Esophageal intraepithelial neutrophils, accompanied by Candida, Cryptosporidium, H. pylori, or Cytomegalovirus (CMV) infections are a frequent finding in these patients. ${ }^{25}$ Esophageal biopsies showed prominent intraepithelial lymphocytosis (IEL) in 50\% of the patients. In the same study, stomach biopsies of $67 \%$ patients lacked plasma cells, and about $20 \%$ had a lymphocytic gastritis pattern. ${ }^{25}$ IELs and villous blunting (mimicking celiac disease) were found in samples of $63 \%$ and $83 \%$ patients respectively. Intraepithelial neutrophils were found in a subset (32\%) and correlated with CMV and Cryptosporidium infections. Granulomas were seen in biopsies from 2 patients $(11 \%) .{ }^{25}$

In the study by Zullo et al, ${ }^{8}$ thirty four consecutive dyspeptic patients with CVID (mean age 49.6 years, range 14-72 years; 17 men) were evaluated by upper gastrointestinal endoscopy and biopsy specimens were taken from the antrum, incisura angularis, and gastric body. $H$. pylori infection was detected in 14/34 (41\%) patients. Chronic active gastritis involving both antrum and body was observed more frequently in $H$. pylori positive $(79 \%)$ than in $H$. pylori negative patients $(\mathrm{p}=0.001)$. Multifocal atrophic gastritis was also more frequent in infected individuals $(\mathrm{p}=0.012)$. Other rare features included dysplasia and adenocarcinoma in the H. pylori positive group. ${ }^{8}$

Over expression of p53 may be observed in the gastric mucosa. It has been hypothesized that both $H$. pylori and p53 alterations may play a role in the gastric carcinogenesis in patients with CVID. Since the GIT is an important barrier to pathogens and is the largest immune organ in the body with a "perpetual state of physiological inflammation" in patients with CVID, with their impaired defense machinery are incapable of handling gut pathogens. Majority of patients show absence of plasma cells in small bowel with prominent lymphoid aggregates in $47 \%$ of patients. ${ }^{25}$

Small Bowel: Malabsorption syndrome in CVID is commonly mistaken for celiac disease. CVID patients exhibit villous atrophy which is thought to be $\mathrm{T}$ cell mediated, but unlike celiac sprue, plasma cells are absent in CVID. Another difference is that in classical sprue, gluten withdrawal leads to normalization of villous architecture but this does not occur in CVID. ${ }^{21,26}$ Infections with H. pylori, Giardia lamblia, and Cryptosporidium are common with small bowel bacterial over growth syndrome. The course of giardiasis in these patients is protracted despite therapy and has a tendency to recur. Giardiasis infection is so common in these patients that an empirical therapy with metroniadazole at the onset of diarrhoea is a common strategy. Cryptosporidium can also account for some degree of villous atrophy in these patients. The incidence of Clostridium difficile however has not been reported to be increased in CVID. Besides this, the patient may have hepatosplenomegaly, lymphadeno-pathy, nodular lymphoid hyperplasia of the gut along with increased permeability in the gut. Thus, immunohisto-logical examinations of intestinal biopsies are required to determine the extent of mucosal immunodeficiency in CVID patients as suggested by Daniels et al. ${ }^{25}$

Large bowel: There is a close association between CVID and inflammatory bowel disease. Lymphocytic colitis pattern was seen in up to $38 \%$ of patients. ${ }^{25}$ Other less common features include collagenous enteritis, colitis, and CMV colitis. Features mimicking ulcerative or 
Crohns' colitis were observed in $43 \%$ of cases. ${ }^{25}$ Other rare features included granulomas, and CMV infection. One study documented a prior diagnosis of celiac disease in $25 \%$ and inflammatory bowel disease in $35 \%$ of cases. ${ }^{26}$ CVID colitis shares features with Graft-Vs-Host disease (GVHD), lymphocytic colitis and ulcerative colitis, including increase of lymphocytes in epithelium and lamina propria and loss of crypts.

\section{$B$ cell defects in CVID:}

Enumeration of the B-cell subsets in peripheral blood may be useful in classification of common variable immunodeficiency. These subsets include class-switched memory B cells (CD27+IgD-IgM-), nonswitched memory B cells $(\mathrm{CD} 27+\operatorname{IgD}+\operatorname{IgM}+), \operatorname{IgM}$ memory B cells $(\mathrm{CD} 27+\operatorname{IgM}$ $\left.+\operatorname{Ig} \mathrm{D}^{\mathrm{dim}}\right)$, transitional B cells (CD38+++ IgM+++), plasmablasts (CD38+++IgM-), mature B cells (CD19+CD21+), and CD21 $1^{\text {low }} \mathrm{B}$ cells (CD19+CD21 ${ }^{\text {low }}$ ). These patients classically have deficiency of classswitched B cells. ${ }^{27}$

Several authors have demonstrated defective B cell intrinsic activation in patients with CVID. Reduced $\mathrm{Ca}^{2+}$ signals are observed in all mature B cell populations of most patients with CVID. ${ }^{28}$ An impaired BCR-induced calcium signalling is associated with the expansion of $\mathrm{CD} 21^{\text {low }} \mathrm{B}$ cells, hypogammaglobulinemia, autoimmune dysregulation, and lymphadenopathy. ${ }^{1}$ Mutations interfering with the regulation of the Ig gene expression, deficiency of memory B cells, and somatic hypermutation (SHM) abnormalities have been reported in patients with common variable immunodeficiency. ${ }^{1} \mathrm{~B}$ cells from these patients are incapable of undergoing isotype switching to up regulate activation markers on $B$ cells when stimulated in vitro and loss of IgM memory B cells correlates with clinical features of recurrent pneumonia caused by encapsulated microbes and bronchiectasis in common variable immunodeficiency. ${ }^{29}$

B cells in CVID can secrete immunoglobulins, although this is often limited to IgM, if given an appropriate in vitro stimulation. Considerable numbers of $\mathrm{J}$ chainsynthesizing cells are present in all patients with CVID, indicating the presence of early B cells unable to differentiate into immunoglobulin-producing plasma cells. ${ }^{30}$

\section{T cells defects in CVID:}

CVID patients with significant $\mathrm{T}$ cell dysfunction including cutaneous anergy, decreased or absent proliferation, and/or lymphokine production in response to recall antigens, mitogens, anti-CD3 or phorbol myristate acetate (PMA) have been described in CVID patients. ${ }^{31}$ Many patients have a defect in $\mathrm{CD} 4^{+} \mathrm{T}$-cell priming to antigens, as measured by the number of circulating responsive $\mathrm{CD}^{+} \mathrm{T}$ cells following immunization. Many patients have lymphopenia due to the low number of $\mathrm{CD}^{+}{ }^{+}$subsets, ${ }^{32}$ increased numbers of $\mathrm{CD} 8+$ lymphocytes and reduced CD4/CD8 ratios $(<1)$. These patients also have decreased production of IL-2 when their peripheral blood mononuclear cells are stimulated in vitro. Inducible co-stimulator (ICOS) deficiency ${ }^{15}$ results in severe B-cell defect, which is caused by impaired T-cell help.

Three primary connections between $\mathrm{T}$ and $\mathrm{B}$ cells comprise the core of the immunological synapse. First, processed protein antigen is presented by class II major histocompatibility complex (MHC) on the B cell to the Tcell-Bcell receptor (TCR) which initiates the interaction. Second, CD28 on the T cell binds to CD80/CD86 on the $\mathrm{B}$ cell, resulting in up-regulation of CD40 ligand (CD154) on the T-cell surface. Third, the newly up-regulated CD40 ligand on the T cell binds to CD40 on the B cells. Thus $\mathrm{T}$ cell - B cell interaction is vital for a normal immune response. Since B cells are defective in CVID, T cell functions are also jeopardized.

\section{Blunted cytokine response:}

Patients suffering from CVID have increased endogenous cyclic adenosine monophosphate (cAMP) levels in $\mathrm{T}$ cells. These cells co-express human leukocyte antigen HLA-DR and IL-2 receptors, suggesting in vivo activation. Approximately $60 \%$ of patients with CVID show diminished proliferative response to TCR stimuli and decreased induction of gene expression for IL-2, IL-4, IL-5, and IFN- . ${ }^{33}$

\section{Dendritic cell (DC) defects:}

A low number and function of DCs is correlated with a greater incidence of autoimmunity, splenomegaly, and granulomatous disease and a higher incidence of clinical complications in CVID. DCs play a role in B-cell growth and differentiation of plasma cells into immunoglobulinsecreting plasma cells and Secrete low amounts of IL12 upon CD40 signalling. ${ }^{34}$

\section{Autoimmune diseases and CVID}

In contrast to X-linked agammaglobulinemia (XLA), common variable immunodeficiency is associated with a high frequency of autoimmune and granulomatous 


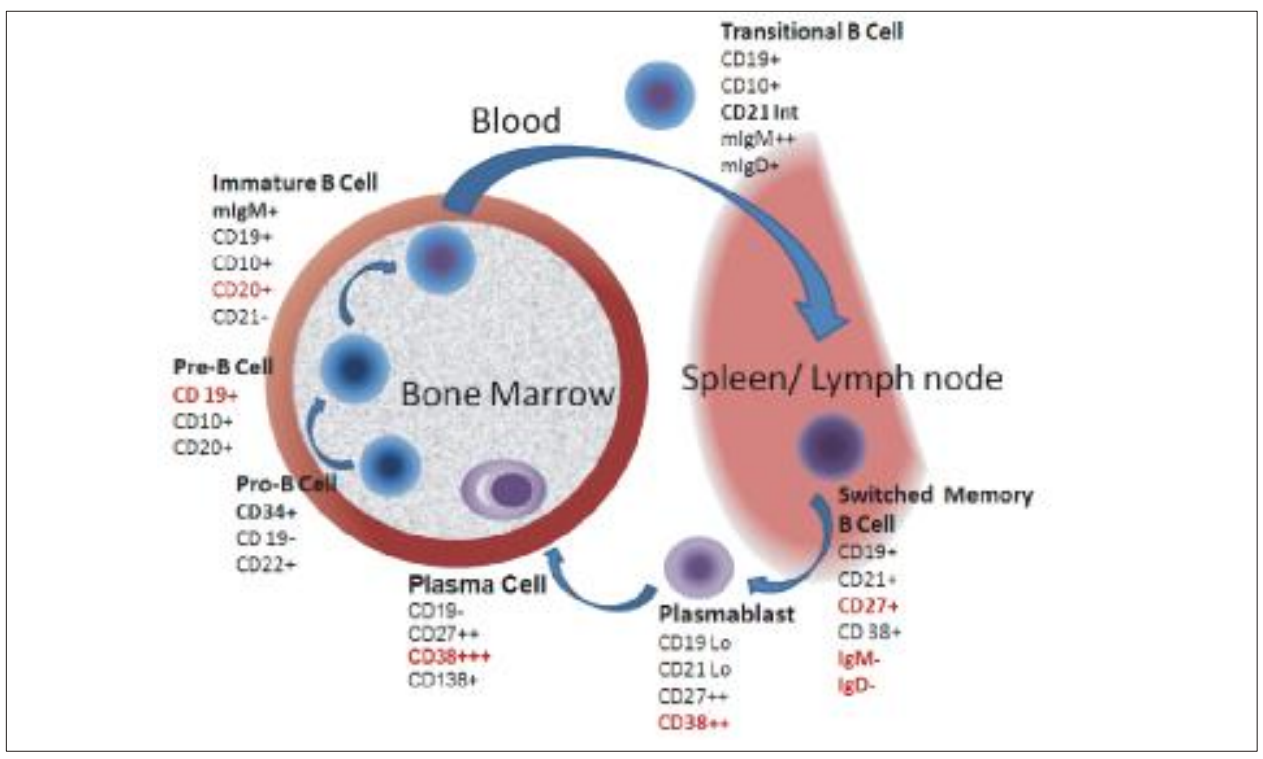

Figure: B Cell defects in CVID: Mutations in CD19, CD20 leading to absent protein expression, deficiency of class switched memory B Cells, and deficiency of CD38+ plasma cells. Adapted from Warnatz Kand Michael S. ${ }^{35}$

diseases. The most common autoimmune conditions in patients with CVID are cytopenias, idiopathic thrombocytopenic purpura (ITP) in particular, and hemolytic anemia or, more rarely, autoimmune neutropenia. ${ }^{10}$ Other solid organ-specific autoimmune diseases (e.g., pernicious anemia, thyroid diseases, vitiligo) have prevalence rates of more than $5 \%$ in patients with CVID, which is higher than in the general population. Other conditions associated with CVID include insulindependent diabetes, psoriasis, systemic lupus erythematosus, rheumatoid arthritis, juvenile rheumatoid arthritis, and uveitis. Approximately $20 \%$ of patients have a severe gastroenteropathy with severe malabsorption, nodular lymphoid hyperplasia, and chronic inflammatory bowel disease, such as ulcerative colitis and Crohns' disease. ${ }^{34}$

Although regular intra-venous immunoglobulin(IVIG) replacement therapy reduces susceptibility to giardiasis and Campylobacter enteritis, it does not prevent autoimmune mucosal inflammation signifying an independent autoimmune injury despite a controlled susceptibility to infection. Recovery of Ig production (mostly IgG and IgM) transiently or permanently has been reported under certain clinical situations in patients with CVID. These cases indicate that CVID is associated with potentially reversible defects in immunoregulatory factors and intact B-cell systems. Currently, there is no standard therapy for the associated gastrointestinal disease other than empirical nutritional intervention for weight loss and anti-diarrheal agents along with antimicrobials and IVIG replacement therapy.

Thus, CVID is associated with variable immune defects, vast array of gastrointestinal manifestations, a celiac like syndrome and is misdiagnosed by clinicians. Therefore, it is important to recognize this entity, as therapy with IVIG and prophylactic antimicrobials can make a substantial difference in the longevity and quality of life of these patients. Gastroenterologist has to be aware of this entity, and suspect a diagnosis in patients with celiac like manifestations, not responding to gluten withdrawal or patients who are anti-tissue transglutaminase or anti-gliadin antibody negative despite a strong clinical suspicion. A simple test such as serum immunoglobulin estimation, under such circumstances, can indicate the diagnosis of CVID, and many of the molecules viz. BAFFR, ICOS, CD20, CD19, and CD81, defective in CVID can also be easily studied by flowcytometry, which is available in most of the diagnostic centers.

\section{REFERENCES}

1. Wehr C, Kivioja T, Schmitt C, Ferry B, Witte T, Eren E, et al. The EUROclass trial: defining subgroups in common variable immunodeficiency. Blood 2008;111(1):77-85.

2. Oksenhendler E, Gerard L, Fieschi C, Malphettes M, Mouillot G, Jaussaud R, et al. Infections in 252 patients with common variable immunodeficiency. Clin Infect Dis 2008;46:1547-54.

3. http://emedicine.medscape.com/article/1051103-overview 
4. Chapel H, Cunningham-Rundles C. Update in understanding common variable immunodeficiency discorders (CVIDs) and the management of patients with these conditions. Br J Haematol 2009;145(6):709-27.

5. Hammarstrom L, Vorechovsky I, Webster D. Selective IgA deficiency (SIgAD) and common variable immunodeficiency (CVID). Clin Exp Immunol 2000;120(2):225-31.

6. Daniels JA, Lederman HM, Maitra A, Montgomery EA. Gastrointestinal tract pathology in patients with common variable immunodeficiency (CVID): a clinicopathologic study and review. Am J Surg Pathol 2007;31(12):1800-12.

7. Washington K, Stenzel TT, Buckley RH, Gottfried MR. Gastrointestinal pathology in patients with common variable immunodeficiency and X-linked agammaglobulinemia. Am J Surg Pathol 1996;20(10):1240-52.

8. Zullo A, A Romiti, V Rinaldi, Vecchione A, Tomao S, Aiuti F, et al. Gastric pathology in patients with common variable immunodeficiency. Gut 1999;45(1):77-81

9. Morimoto Y, Routes JM. Granulomatous disease in common variable immunodeficiency. Curr Allergy Asthma Rep 2005;5:370-5.

10. Knight AK, Cunningham-Rundles C. Inflammatory and autoimmune complications of common variable immune deficiency. Autoimmun Rev 2006;5:156-9.

11. Swierkot J, Lewandowicz-Uszynska A, Chlebicki A, SzmyrkaKaczmarek M, Pola?ska B, Jankowski A, et al. Rheumatoid arthritis in a patient with common variable immunodeficiency: difficulty in diagnosis and therapy. Clin Rheumatol 2006;25(1):92-4.

12. Cunningham-Rundles C, Bodian C. Common variable immunodeficiency: clinical and immunological features of 248 patients. Clin Immunol 1999;92(1):34-48.

13. Ogershok PR, Hogan MB, Welch JE, Corder WT, Wilson NW. Spectrum of illness in pediatric common variable immunodeficiency. Ann Allergy Asthma Immunol 2006; 97(5):653-6.

14. Rosenow EC 3rd, Hurley BT. Disorders of the thymus. A review. Arch Intern Med 1984;144:763-70.

15. Tafuri A, Shahinian A, Bladt F, Yoshinaga SK, Jordana M, Wakeham A, et al. ICOS is essential for effective T- helper-cell responses. Nature 2001;409(6816):105-9.

16. Castigli E, Wilson SA, Garibyan L, Rachid R, Bonilla F, Schneider $\mathrm{L}$, et al. TACI is mutant in common variable immunodeficiency and IgA deficiency. Nat Genet 2005;37(8):829-34.

17. van Zelm MC, Reisli I, van der Burg M, Castano D, van Noesel CJ, van Tol MJ, et al. An antibody-deficiency syndrome due to mutations in the CD19 gene. N Engl J Med 2006;354(18):190112.

18. Thompson JS, Bixler SA, Qian F, Vora K, Scott ML, Cachero TG, et al. BAFF-R, a newly identified TNF receptor that specifically interacts with BAFF. Science 2001;293:2108-11.

19. http://www.medscape.com/viewarticle/733149 3

20. van Zelm MC, Smet J, Adams B, Mascart F, Schandene L, Janssen F, et al. CD81 gene defect in humans disrupts CD19 complex formation and leads to antibody deficiency. J Clin Invest 2010;120(4):1265-74.

21. Lai Ping So A, Mayer L. Gastrointestinal manifestations of primary immunodeficiency disorders. Semin gastrointest Dis 1997;8:22-32.

22. Moriuchi H, Takayanagi T, Yamasaki S, Yasui M, Mori K, Yanai $M$, et al. Pernicious anemia in a patient with hypogammaglobulinemia. Acta Paediatr Jpn 1990;32(3):311-4.

23. den Hartoq G, van der Meer JW, Jansen JB, van Furth R, Lamers CB. Decreased gastrin secretion in patients with late-onset hypogammaglobulinemia. N Engl J Med 1988,318(24):1563-7.

24. den Hartoq G, Jansen JB, van der Meer JW, Lamers CB. Gastric abnormalities in humoral immune deficiency syndromes. Scand J Gastroenterol Suppl 1992;194:38-40.

25. Daniels JA, Lederman HM, Maitra A, Montgomery EA. Gastrointestinal tract pathology in patients with common variable immunodeficiency (CVID): a clinicopathologic study and review. Am J Surg Pathol 2007;31(12):1800-12.

26. Heneghan MA, Stevens FM, Cryan EM, Warner RH, McCarthy CF. Celiac sprue and immunodeficiency states: a 25-year review. J Clin Gastroenterol 1997;25(2):421-5.

27. Warnatz K, Denz A, Drager R, Braun M, Groth C, Wolff-Vorbeck $\mathrm{G}$, et al. Severe deficiency of switched memory B cells (CD27(+) $\operatorname{IgM}(-) \operatorname{IgD}(-)$ in subgroups of patients with common variable immunodeficiency: a new approach to classify a heterogeneous disease. Blood 2002;99(5):1544-51.

28. Foerster C, Voelxen N, Rakhmanov M, Keller B, Gutenberger S, Goldacker $\mathrm{S}$ et al. B cell receptor mediated calium signaling is impaired in B-lymphocytes of type Ia patients with common variable immunodeficicency. J Immunol 2010;184(12):7305-13.

29. Carsetti R, Rosado MM, Donnanno S, Guazzi V, Soresina A, Meini A, et al. The loss of IgM memory B cells correlates with clinical disease in common variable immunodeficiency. J Allergy Clin Immunol 2005;115(2):412-7.

30. Herbst EW, Armbruster M, Rump JA, Buscher HP, Peter HH. Intestinal B cell defects in common variable immunodeficiency. Clin Exp Immunol 1994;95(2):215-21.

31. North ME, Spickett GP, Allsop J, Webster AD, Farrant J. Defective DNA synthesis by T cells in acquired 'common variable' hypogammaglobulinaemia on stimulation with mitogens. Clin Exp Immunol 1989;76(1):19-23.

32. Aukrust P, Muller F, Froland SS. Elevated serum levels of interleukin-4 and interleukin-6 in patients with common variable immunodeficiency (CVI) are associated with chronic immune activation and low numbers of CD4+ lymphocytes. Clin Immunol Immunopathol 1994;70:217-24.

33. http://emedicine.medscape.com/article/885935-overview\#a0104

34. Cunningham-Rundles C, Radigan L. Deficient IL-12 and dendritic cell function in common variable immune deficiency. Clin Immunol 2005;115(2):147-53.

35. Warnatz K, Schlesier M. Flowcytometric phenotyping of common variable immunodeficiency. Cytometry B Clin Cytom 2008;74(5):261-71. 


\section{PDF created with pdfFactory Pro trial version www.pdffactory.com}

